\title{
RELAÇÃO ENTRE BEM-ESTAR E RESILIÊNCIA EM HABITAÇĀO DE INTERESSE SOCIAL
}

\author{
ARAÚJO, Geovanna Moreira \\ Universidade Federal de Uberlândia, e-mail: igeovannaraujo@gmail.com \\ VILLA, Simone Barbosa \\ Universidade Federal de Uberlândia, e-mail: simonevilla@ufu.br
}

\begin{abstract}
RESUMO
A habitação de interesse social no Brasil se encontra dentro de um cenário de escassez de recursos, atendendo de forma precária as amplas e variadas necessidades básicas dos usuários, ocasionando uma negativa noção de bem-estar. Além de demonstrarem pouca resiliência, onde o ambiente construído absorve e responde de maneira mínima aos impactos sofridos, não promovendo uma adaptação positiva dos espaços. Este trabalho apresenta análises preliminares a partir de dados coletados por Avaliação Pós-Ocupação de uma pesquisa de mestrado em andamento no Programa de Pós-Graduação em Arquitetura e Urbanismo da Universidade Federal de Uberlândia. Esta, investiga a relevância e a relação da resiliência no ambiente construído em HIS e do bem-estar dos usuários, a partir da ótica do Five Ways to Wellbeing. Tem como objetivo final disponibilizar aos usuários soluções que contribuam para o bem-estar, ampliando a resiliência no ambiente construído em que habitam. Para isso, serão desenvolvidos instrumentos de avaliação e divulgação dos resultados em ambiente computacional.
\end{abstract}

Palavras-chave: Bem-Estar, Resiliência, Avaliação Pós-Ocupação, Ambiente Construído, Habitação de Interesse Social.

\begin{abstract}
Housing of social interest in Brazil is within a scenario of scarcity of resources, serving precariously the wide and varied basic needs of users, causing a negative notion of well-being. In addition to showing little resilience, where the built environment absorbs and responds in a minimal way to the impacts suffered, not promoting a positive adaptation of the spaces. This work presents preliminary analyzes based on data collected by Post-Occupational Assessment of a master's degree in progress in the Post-Graduate Program in Architecture and Urbanism of the Federal University of Uberlandia. It investigates the relevance and the relationship of resilience to the environment built on HIS and the well-being of users, from the perspective of Five Ways to Wellbeing. Its ultimate goal is to provide users with solutions that contribute to well-being, increasing resilience in the built environment in which they live. For this, tools for evaluation and dissemination of the results in computational environment will be developed.
\end{abstract}

Keywords: Wellbeing, Resilience, Post-Occupancy Assessment, Built Environment, Housing of Social Interest.

\section{INTRODUÇÃO}

O presente trabalho deriva de uma pesquisa de mestrado em andamento no Programa de Pós-Graduação em Arquitetura e Urbanismo da Universidade Federal de Uberlândia, intitulada "Resiliência e Bem-Estar no Ambiente

ARAÚJO, G. M.; VILLA, S. B. Relação entre bem-estar e resiliência em Habitação de Interesse Social. In: SIMPÓSIO BRASILEIRO DE QUALIDADE DO PROJETO NO AMBIENTE CONSTRUÍDO, $6 .$, 2019, Uberlândia. Anais... Uberlândia: PPGAU/FAUeD/UFU, 2019. p. 1364-1376. DOI https://doi.org/10.14393/sbqp19123. 
Construído em Habitação de Interesse Social: avaliação e análise". Inserindo no escopo de pesquisa institucional: "[BER_HOME] Assessing The Built Environment Resilience in Brazilian Social Housing".

A pesquisa investiga os mecanismos de resiliência no ambiente construído em habitação de interesse social (HIS), de forma a promover o bem-estar dos moradores. Para tanto, serão aplicados instrumentos de Avaliação PósOcupação (APO) para observação dos comportamentos, sentimentos, expectativas e aspirações dos moradores, bem como delimitação de impactos, fragilidades, recursos e potencialidades que condicionam um ambiente resiliente e que promove $\mathrm{O}$ bem-estar dos moradores. Os instrumentos de APO serão aplicados/testados em dois estudos de casos na cidade de Uberlândia- MG.

O presente artigo apresenta parte da pesquisa de mestrado enfocando sua fundamentação teórica, a predefinição dos atributos a serem avaliados e os resultados preliminares da aplicação do instrumento de avaliação de impactos em um estudo de caso.

\section{METODOLOGIA}

A presente pesquisa basear-se sua metodologia no método conhecido como Design Science Research (DSR). A DSR procura reduzir a distância entre teoria e a prática, mantendo o rigor necessário para garantir confiabilidade dos resultados das pesquisas. O principal objetivo do método é projetar e construir um artefato, prescrever soluções, estudar, pesquisar e investigar o artificial e seus comportamentos. De forma que esse artefato criado seja o produto final da pesquisa, podendo assim levar as soluções à gestores, empresas e até à própria comunidade (DRESCH; LACERDA; JUNIOR, 2015). Nesse sentido, a intenção do trabalho é produzir um artefato, ambiente computacional (página na web e aplicativo), que avalie e disponibilize os resultados da pesquisa, oferecendo soluções que permitam ampliar o bem-estar dos usuários em suas moradias. Pretende-se que esse artefato, orientado ao usuário, seja mais intuitivo, eficiente e interativo.

Entender como se dá o movimento de adaptação no interior de um certo conjunto de habitações de interesse social, por meio de registros da APO, fornece ricos fundamentos para consulta e evolução do conceito de resiliência, abastecendo diversos atores sociais com material atual, confiável e pertinente para fundamentar seus empreendimentos. Alinhado a isso, a pesquisa aqui descrita irá se utilizar da APO e Análise de Projetos.

A APO destaca-se como importante ferramenta na obtenção de dados consistentes relativos ao ambiente construído (ONO et al., 2018; VILLA et al., 2015; MALLORY-HILL; PREISER; WATSON, 2012; COLE, 2005), da mesma maneira que na identificação de impactos em que o meio está sujeito, suas fragilidades, recursos e potencialidades. Sua utilização permite a montagem e observação, por parte dos agentes envolvidos, de bancos de dados alimentados por avaliações que incluam a percepção física do ambiente construído, além da interação entre esse ambiente e o comportamento dos usuários (STEVENSON, 2015; LEAMAN; BORDASS; ELEY, 2006; VILLA, 2008; VILLA; SARAMAGO; GARCIA, 2015).

Para a avaliação e análise do bem-estar será utilizado como parâmetro o Five Ways To Well-Being (5W) - Cinco Caminhos para o Bem-Estar - que consiste em 
comportamentos desenvolvidos pelos indivíduos de modo a gerarem maior bem-estar (AKED et al., 2008).

Os estudos de caso escolhidos para o desenvolvimento da pesquisa são localizados na cidade de Uberlândia: (i) um empreendimento horizontal do Programa Minha Casa Minha Vida, caracterizado por casas geminadas, denominado Residencial Sucesso Brasil - Bairro Shopping Park; (ii) empreendimento vertical do Programa Minha Casa Minha Vida, caracterizado por edifícios com estrutura autoportante, denominado Conjunto Córrego do Óleo, loteamento um. Contudo, até o presente momento foram aplicados questionários apenas em um dos estudos de caso, na intenção de identificar os impactos e o nível de incomodo dos moradores.

\section{RESILIÊNCIA E BEM-ESTAR: UMA RELAÇÃO NECESSÁRIA}

\subsection{Resiliência no ambiente construído em habitação de interesse social}

Os principais desafios da HIS no Brasil são os cenários de recursos mau otimizados e a precariedade de suas unidades habitacionais entregues. Estas observações tornam-se notáveis no programa de habitação do governo federal: Programa Minha Casa Minha Vida (PMCMV), implantado no país em 2009. No qual, tornou-se alvo de pesquisas que buscarem melhorias nas moradias entregues pelo governo. Várias destas pesquisas tem demostrado que as unidades atendem de forma precária as amplas e variadas necessidades básicas dos usuários (FGV; INSTITUTO ESCOLHAS, 2019; AMORE; SHIMBO; RUFINO, 2015; ANGÉLl; HEHL, 2014; ORNSTEIN, 2005), ocasionando uma negativa noção de bem-estar. Também, tais empreendimentos têm demostrado pouca resiliência, já que seus ambientes construídos absorvem e respondem de maneira mínima aos impactos sofridos, além de não promoverem uma adaptação positiva dos espaços.

Neste contexto, entende-se por resiliência, no âmbito do ambiente construído, como a capacidade deste em se adaptar e transformar positivamente para lidar com as mudanças e impactos sofridos ao longo do tempo (GARCIA; VALE, 2017; PICKETT et al., 2014; MAGUIRE; CARTWRIGHT, 2008).

O fato de existir inúmeras estratégias relacionada a diferentes configurações do espaço e de usuários é importante que o ambiente construído seja adaptável. Isto é particularmente importante em um contexto de grandes mudanças demográficas, climáticas, de estilo de vida e de disponibilidade de novas tecnologias. O ambiente construído deve responder às necessidades, comportamentos e desejos dos usuários. Oferecendo, assim, liberdade de escolha e controle sobre estes (STEEMERS, 2015).

Para aprimorar a resiliência em um sistema é necessário saber de onde começa - o que implica em medir algo -, e onde precisa saber para onde vai, o que implica traçar possibilidades (GARCIA; VALE, 2017). Identificar quais são as ameaças incidentes, encontrar o que está exposto (material e população) e a vulnerabilidade especifica local é o primeiro passo para determinar as ações adaptativas que visam a resiliência em um sistema urbano. Assim, importa conhecer os impactos que incidem sobre o sistema, observar sua repercussão sobre o conjunto: se origina capacidade adaptativa ou vulnerabilidade. A partir disso, traças objetivos para amenizar a vulnerabilidade de potencializar a capacidade adaptativa. 


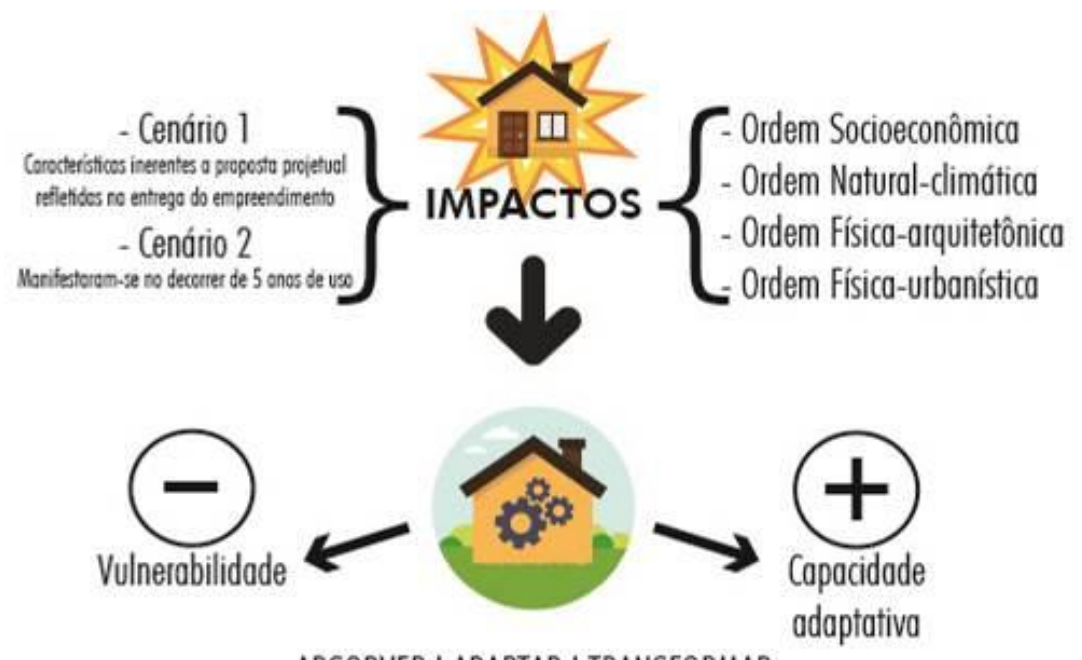

ABSORVER I ADAPTAR I TRANSFORMAR

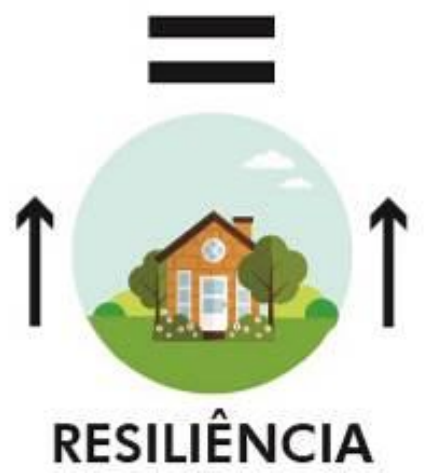

Figura 1 - Diagrama sobre como ocorre o aumento da resiliência Fonte: Autoras (2019)

Tabela 1 - Conceituação do termo Impacto dentro da pesquisa

\begin{tabular}{|c|c|c|}
\hline \multicolumn{3}{|r|}{ IMPACTOS SOBRE O AMBIENTE CONSTRUIDO DERIVA DE: } \\
\hline \multicolumn{2}{|c|}{$\begin{array}{l}\text { CAUSAS } \\
\text { (Grandes Eventos) }\end{array}$} & $\begin{array}{l}\text { Origem, motivo ou razão para que algo aconteça (Dicionário). Refere- } \\
\text { se a grandes eventos decorridos no tempo e no espaço que fazem } \\
\text { parte da vida no planeta Terra (GARCIA \& VALE, 2018). Podem ser de } \\
\text { ordem climática, ambiental, social, econômica e/ou política. }\end{array}$ \\
\hline \multirow{3}{*}{$\sum_{\substack{4 \\
4}}^{\frac{4}{4}}$} & \multicolumn{2}{|c|}{$\begin{array}{l}\text { Ameaças referem-se aos fenômenos climáticos, ambientais, sociais, econômicos e/ou } \\
\text { políticos incidentes sobre o urbano capazes de gerar efeitos sensíveis sobre o } \\
\text { ambiente construído das unidades habitacionais, na medida de sua vulnerabilidade. } \\
\text { Podem classificar-se como: }\end{array}$} \\
\hline & $\begin{array}{l}\text { CHOQUES } \\
\text { AGUDOS }\end{array}$ & $\begin{array}{l}\text { Choques repentinos, derivados de eventos agudos que ameaçam uma } \\
\text { cidade (ARUP \& THE ROCKEFELLER FOUNDATION, 2015). }\end{array}$ \\
\hline & $\begin{array}{l}\text { ESTRESSES } \\
\text { CRONICOS }\end{array}$ & $\begin{array}{l}\text { Desastres lentos que enfraquecem o tecido de uma cidade (ARUP \& } \\
\text { THE ROCKEFELLER FOUNDATION, 2015). }\end{array}$ \\
\hline \multicolumn{2}{|c|}{$\begin{array}{l}\text { EFEITOS } \\
\text { NEGATIVOS }\end{array}$} & $\begin{array}{l}\text { Prejuízos sofridos ou causados por algo ou alguém (ex.: danos físicos, } \\
\text { morais, patrimoniais) (Dicionário). Mais especificamente, referem-se às } \\
\text { consequências negativas das ameaças incidentes sobre bens e } \\
\text { pessoas, que geram patologias no ambiente construído e enfraquecem } \\
\text { laços sociais e afetivos entre moradores e entre estes e o ambiente } \\
\text { construído que ocupam. No contexto do ambiente construído de } \\
\text { unidades habitacionais de interesse social, podem ser percebidos nas } \\
\text { escalas do terreno, da estrutura, das vedações verticais e horizontais, } \\
\text { das infraestruturas, dos ambientes e mobiliários (BRAND, 1994). Sua } \\
\text { extensão deriva da e amplifica a sensibilidade/susceptibilidade do } \\
\text { ambiente construído às ameaças, ou seja, sua vulnerabilidade. }\end{array}$ \\
\hline
\end{tabular}

Fonte: Autoras (2019)

O termo impacto refere-se ao conjunto de choques agudos e/ou estresses crônicos que ameaçam às vidas, meios de subsistência, saúde, ecossistemas, 
economias, culturas, serviços e infraestrutura de uma sociedade e ambiente construído expostos, gerando efeitos negativos proporcionais ao seu estado de vulnerabilidade em um dado momento. Os impactos incidentes sobre 0 urbano e seus sistemas são causados, a priori, por grandes eventos ou desafios globais, com os quais os governos e a sociedade como um todo tem se deparado contemporaneamente, chamando para si grande atenção. Motivam, ao redor de todo o mundo, pesquisas que visam seu enfrentamento e a minimização de seus efeitos negativos sobre os ambientes natural e construído (ARUP; THE ROCKEFELLER FOUNDATION, 2015; GARCIA; VALE, 2018; ELIAS-TROSTMANN et al., 2018; LEMOS, 2010).

\subsection{Five Ways (5W) para o Bem-estar}

Diante disso, torna-se importante promover um ambiente construído dotado de qualidades mínimas necessárias relacionadas à resiliência, a partir de estratégias que favorecem o bem-estar em HIS. O significado de bem-estar está relacionado diretamente ao estado do indivíduo. Sendo assim, o governo britânico estabeleceu os $5 \mathrm{~W}$ a partir de evidencias analisadas na vida da população. Esses $5 \mathrm{~W}$ são ações acessíveis aos indivíduos para que melhorem seu bem-estar pessoal, ou seja, são ações comportamentais que podem ser utilizadas por comunidades, organizações, poderes públicos para ajudar, apoiar e melhor a qualidade de vida das pessoas (ADEK; THOMPSON, 2011). Essas ações consistem em: (i) Conectar; (ii) Continuar Aprendendo; (iii) Tomar Conhecimento; (iv) Ser Ativo; e (v) Doar.
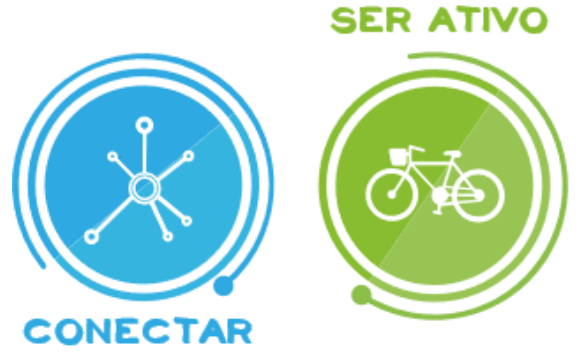

Figura 2 - Five Ways para o bem-estar -

Fonte: Autoras (2019)
TOMAR

CONHECIMENTO
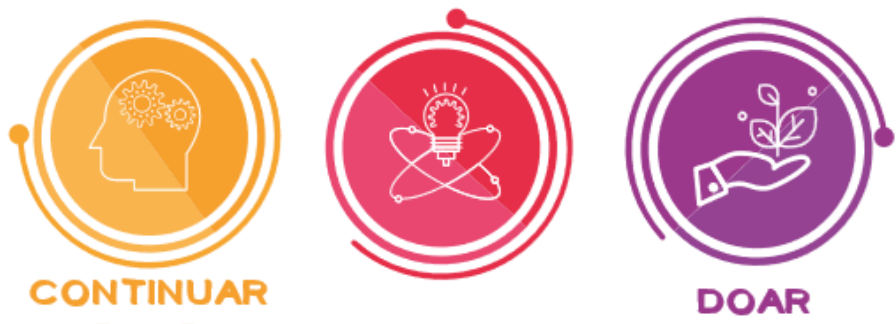

A abordagem do 5W foi adotada como intervenção "downstream" e/ou "upstream". Intervenções "downstream" consiste em motivar os indivíduos a fazerem mudanças por sua própria vontade, enquanto intervenções "upstream" é sobre o mudar o ambiente em que os comportamentos se desenvolvem, podendo assim, promover novas alternativas (AKED; THOMPSON, 2011). Desta forma, entende-se que promover um espaço que facilite 0 desenvolvimento dos $5 \mathrm{~W}$ contribui para o bem-estar dos usuários.

i. Conectar: dentro do ambiente construído esse indicador pode ser percebido nas formas como 0 ambiente contribui para 0 desenvolvimento de relacionamentos, locais que criam oportunidades das pessoas se conectarem. Como exemplo espaços com fácil acesso e com proximidade de equipamentos públicos e de uso comum (escolas, mercados, entre outros) e que apoiam encontros casuais. 
ii. Continuar Aprendendo: dentro do ambiente construído esse indicador entende que o ambiente físico do lar e da sala de aula possuem grande influencia no desenvolvimento intelectual. $O$ ambiente construído precisa ser confortável fisicamente, seguro, iluminado, silencioso e apresentar boa circulação de ar (STEEMERS, 2015).

iii. Tomar Conhecimento: dentro desse indicador o ambiente construído pode fornecer espaços expositivos, áreas de contemplação paisagismo, bancos, entre outras estratégias arquitetônicas possibilitam a observação significativa das pessoas, fazendo-as para e prestar atenção ao seu redor (STEEMERS, 2015).

iv. Ser ativo: esse indicador apresenta as características de projeto associado ao aumento de atividade física incluem acesso a instalações esportivas, calcadas arborizadas confortável para 0 andar e desenvolvimento de caminhadas. No ambiente construído interno o desenvolvimento de espaços que possibilitam o exercício físico pode ser feito de forma simples como circulações adequadas, ambientes em diferentes níveis com uso de escadas (STEEMERS, 2015).

v. Doar é entendido como sentimento altruísta, em ser educado, ajudar ao próximo. Há evidencias que as pessoas são menos altruístas em ambientes urbanos do que nos rurais, o que confirma que o contato com espaços verdade, interação com a natureza são valiosos (STEEMERS, 2015). Por isso, a necessidade de desenvolver ambientes com características físicas positivas, como diversidade de usos, fáceis acessos, acessibilidade e qualidade espacial e visual.

Tabela 2 - Predefinição dos indicadores do Five Ways no ambiente construído

\begin{tabular}{|c|c|c|}
\hline ATRIBUTO & INDICADORES & SUBINDICADORES \\
\hline \multirow{25}{*}{ BEM-ESTAR } & \multirow{5}{*}{$\begin{array}{c}\text { CONECTAR } \\
\text { es sobre conectar com as pessoas. } \\
\text { relacionamentos com visinhos, familiares e } \\
\text { amigos. }\end{array}$} & Acesso de Serviços Locais: \\
\hline & & Espaços para desenvolvimento de atividades: \\
\hline & & Areas adequadas para interaçăo; \\
\hline & & Ambientes adaptáveis: \\
\hline & & Privacidade: \\
\hline & \multirow{3}{*}{$\begin{array}{c}\text { SER ATIVO } \\
\text { é sobre deservolvimento de otividades } \\
\text { fisicas, seja correr, andar de bicicleta. } \\
\text { praticorum erpodte, dancor. }\end{array}$} & Espaços públicos de Usos Diversos: \\
\hline & & Fácil acesso a espaços públicos: \\
\hline & & Quadras poliesportivas, playgrounds: \\
\hline & \multirow{8}{*}{$\begin{array}{l}\text { CONTINUAR APRENDENDO } \\
\text { es sobre aprender colsas novas, seja } \\
\text { aprender a tocar um instrumento musical, } \\
\text { aprender sobre jardinagem, culinatia. } \\
\text { entre outros. }\end{array}$} & Espaços de usos diversos (pomares, hortas, etc.): \\
\hline & & Acesso fácil a instifuiçoes de ensino: \\
\hline & & Espaços calmos e silenciosos: \\
\hline & & Locais de uso público para aprendizagem: \\
\hline & & Escolas locais: \\
\hline & & Ambientes adaptóveis: \\
\hline & & Boa acústica. luminação. ventilaçào \\
\hline & & Limpeza: \\
\hline & \multirow{3}{*}{$\begin{array}{c}\text { TOMAR CONHECIMENTO } \\
\text { 6 sobre ter conscilencia das coisas ao seu } \\
\text { redor, dos sentimentos, } \\
\text { guteconhecimento. }\end{array}$} & Espaços públicos abertos (áreas verdes): \\
\hline & & Ambientes flexiveis, adaptáveis: \\
\hline & & Privacidade: \\
\hline & \multirow{6}{*}{$\begin{array}{c}\text { DOAR } \\
\text { es sobre ajudar o prónimo, voluntoriarse } \\
\text { em projetos socials entre outras afividades. }\end{array}$} & Espaços públicos abertos: \\
\hline & & Espaços adequados para receber visitas: \\
\hline & & Ambientes de convivio; \\
\hline & & Diversidade de Usos: \\
\hline & & Acessibilidade: \\
\hline & & Proximidade; \\
\hline
\end{tabular}


Não existem soluções universais para garantir que todos os parâmetros de bem-estar sejam desenvolvidos e otimizados, porém os profissionais da área, no mínimo devem garantir que as estratégias projetuais que facilitam e promovem o bem-estar alcancem níveis satisfatórios e relativamente bons, sem afetar e impactar negativamente a qualidade de vida dos usuários (STEEMERS, 2015).

\subsection{Identificando os Impactos ocorrentes}

Visando o entendimento sobre o termo "impacto" e buscando identificar as ameaças presentes no estudo de caso escolhido foi desenvolvida um instrumento para constatar os impactos presentes. Tal instrumento consiste em um questionário voltado para os moradores das unidades habitacionais entregues pelo programa MCMV, investigando o nível de incomodo gerado a partir da percepção dos indivíduos ao longo do tempo de uso.

Uma pesquisa em APO tem como objetivo principal verificar o nível de satisfação do usuário com o ambiente construído durante o seu tempo de uso. Sendo assim o questionário é a ferramenta mais efetiva para atingir tal objetivo, uma vez que, este consiste em um instrumento para coleta de dados diretamente com o próprio usuário (ONO, R.; et al, 2018).

O questionário foi elaborado em formato de perguntas estruturadas, ou seja, fechadas, pois possui uma ou mais alternativas (Figura 3). Onde o usuário respondente teria de escolher quais dos efeitos negativos - impactos identificados por eles desde a entrega da casa até o presente momento, ou seja, impactos percebidos ao longo do tempo. Além de indicar o seu nível de incomodo gerado por aquele problema (muito ou pouco).

\begin{tabular}{|l|l|l|l|l|l|}
\hline \multicolumn{5}{|c|}{ CAUSA (GRANDE EVENTO): APLICAÇÃO INCOMPLETA DO PROGRAMA } \\
\hline \multicolumn{1}{|c|}{ Ameaças } & \multicolumn{2}{|c|}{ Efeitos Negativos sobre a casa e a família } & \multicolumn{2}{c|}{ Nivel de incômodo } & Comentários \\
\hline \multirow{3}{*}{$\begin{array}{l}\text { () ) Falta de qualidade } \\
\text { nas áreas públicas } \\
\text { (ruas) }\end{array}$} & () Ciclovias descontinuas & () Pouco & () Muito & () NA & \\
\cline { 2 - 5 } & $\begin{array}{l}\text { () Ruas e calçadas desconfortáveis para caminhas } \\
\text { () Não apropriação da calçada e rua (permanecer, } \\
\text { conversar com o vizinho, etc) }\end{array}$ & () Pouco & () Muito & () NA \\
\cline { 2 - 5 } & () ) Falta de arborizaçăo - sombreamento & () Muito & () NA & \\
\hline
\end{tabular}

Figura 3 - Exemplo do formato do instrumento desenvolvida para Identificação dos impactos -

Fonte: Autoras (2019)

Tais questionários foram aplicados no loteamento Sucesso Brasil situado no Bairro Shopping Park, Uberlândia. O bairro integrado é composto por quatorze empreendimentos, sendo que o loteamento escolhido possui 175 unidades habitacionais. Para amostragem foram aplicados questionários em quarenta casas do loteamento, contabilizando $20 \%$ do total da comunidade. 0 conjunto é caracterizado por residências geminadas de área útil interna igual a $33,4 \mathrm{~m}^{2}$ (Figura 4), separadas por uma parede compartilhada entre os quartos e que não superam o forro em altura, ocasionando desconforto acústico e falta de privacidade, sendo este os principais impactos relatados pelos moradores (85\%).

Esse problema de acústica este ligado a alguns indicadores do $5 \mathrm{~W}$ - Conectar, Continuar Aprendendo, Tomar Conhecimento e Doar - uma vez que os ruídos podem gerar desentendimentos entre os vizinhos e interferir na privacidade do 
morador (85\%), impedindo suas atividades de concentração e autoconhecimento.
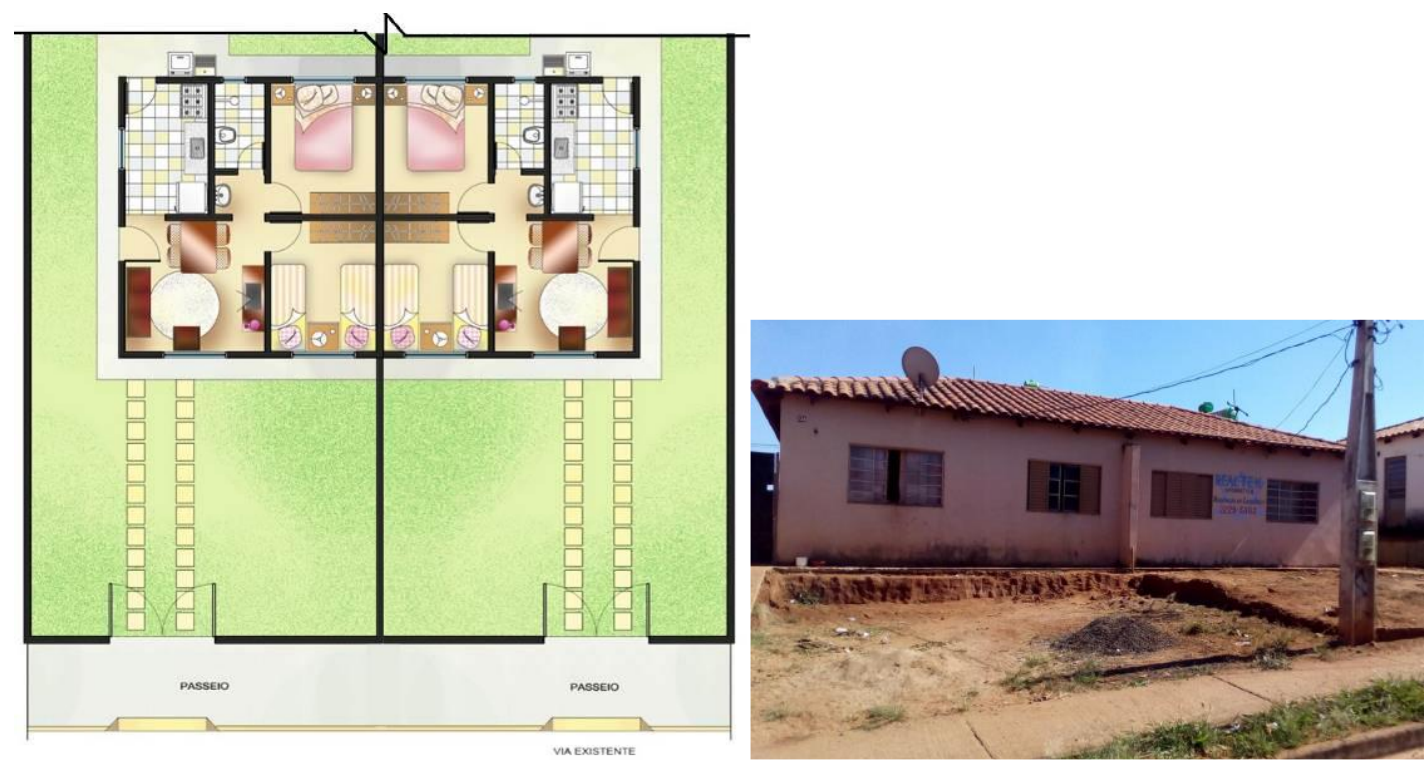

Figura 4 - Tipologia da Unidade Habitacional e foto da fachadas das unidades Fonte: VILLA et al. (2017)

Devido a forma de implantação do PMCMV, muitas vezes construídos em regiões periféricas da cidade por causa do baixo custo da terra (FGV; INSTITUTO ESCOLHAS, 2019), esses conjuntos HIS acabam carentes de infraestrutura e desconectados do restante da cidade. Esse tipo de impacto foi identificado pelos moradores respondentes sentem falta de conexão (60\%) e isolamento com relação ao restante da cidade (52,5\%), uma vez que o sistema de transporte público existente, que seria a forma de ligação/conexão para os moradores, é considerado por eles ineficiente (Figura 5).

Tais impactos estão relacionados com os indicadores conectar, ser ativo e tomar conhecimento, uma vez, que os moradores se sentem desconectados do restante da cidade, acabam negligenciando o uso das áreas públicas, usando somente o automóvel para chegar aos locais desejados, por meio de vias de fluxo rápido, e não percebem as paisagens da cidade em sua volta. Acabam assim, não criando identidade com os locais por onde passam quase todos os dias.

\section{Localização Periférica}

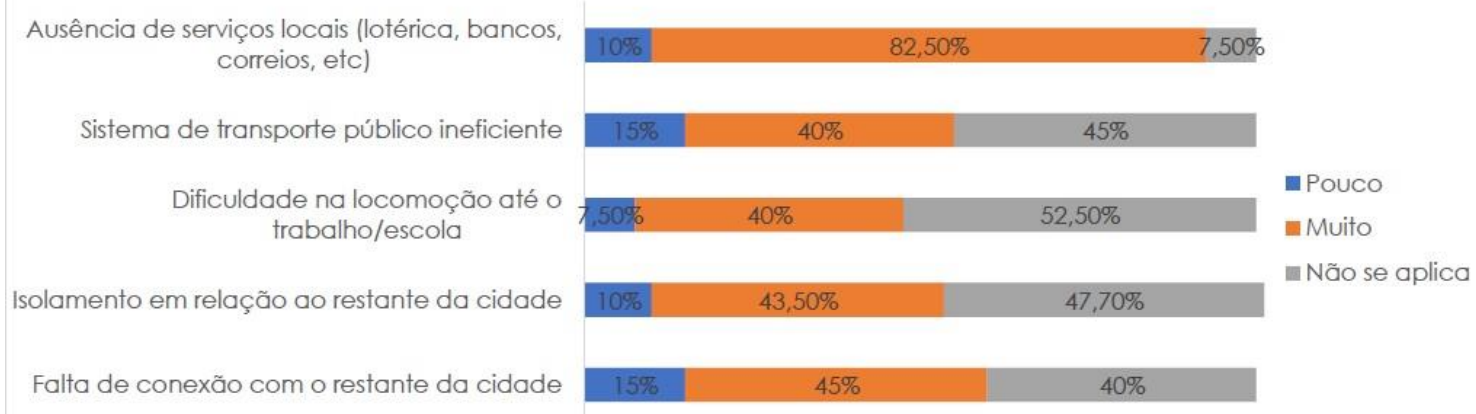

Figura 5 - Gráfico do grau de incômodo em relação à localização do bairro Fonte: Autoras (2019) 
Outro problema identificado é a falta de qualidade urbanística no bairro (Figura 7 e 8), onde as calçadas e ruas são desconfortáveis para andar, interferindo no indicador ser ativo, visto que os moradores não usam as ruas para caminhadas e desenvolvimento de atividades para saúde física, devido ao grande desnível, descontinuidade da pavimentação e a falta de arborização (Figura 6). Além de se sentirem inseguros nas poucas áreas de lazer existente devido a prática de atividades ilícitas nestes locais (Figura 8), o que pode acabar levado a falta de convívio e usos desses equipamentos e áreas públicas. Grande parte dos moradores acreditam que se essas áreas públicas tivessem uma melhor qualidade traria vitalidade urbana para 0 bairro, convidando-os a usufruir dos espaços públicos do bairro.
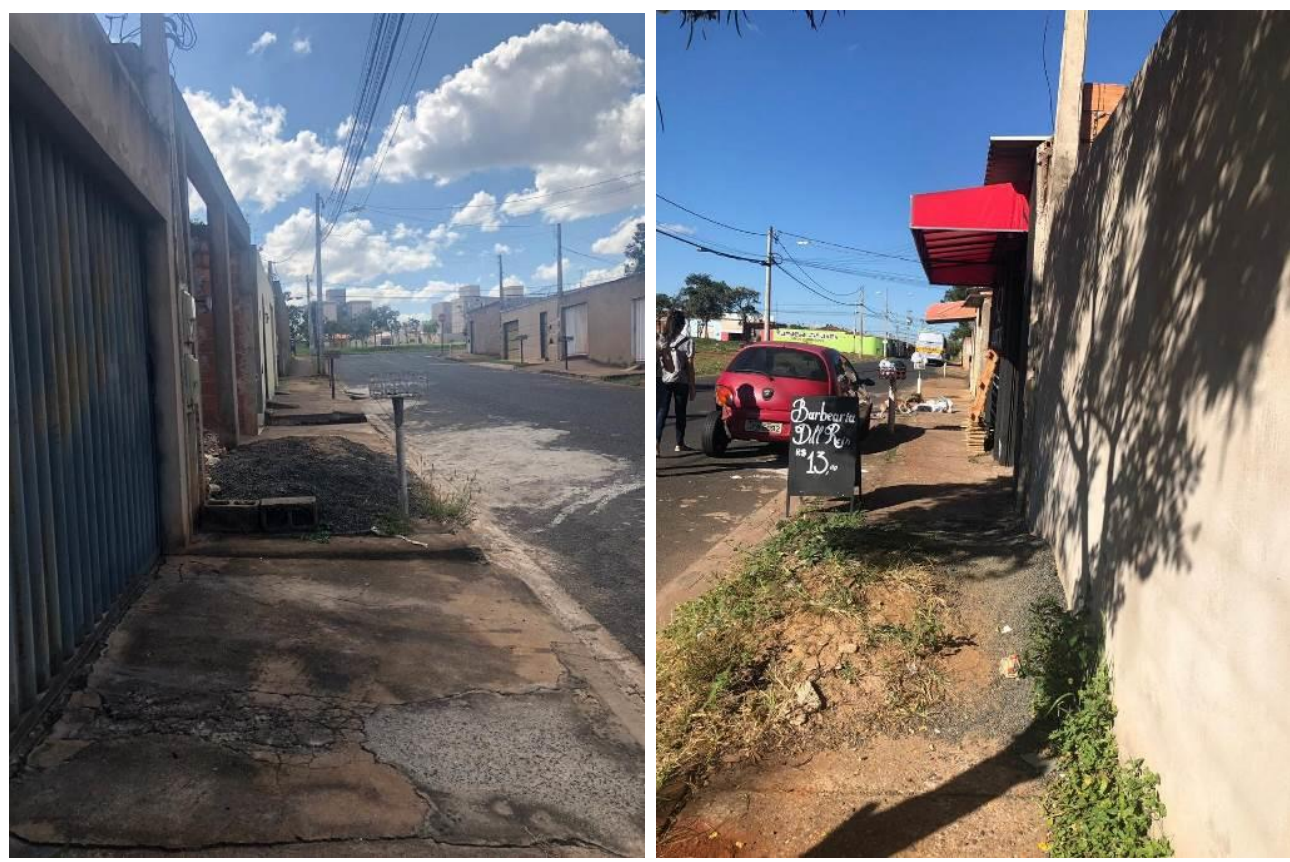

Figura 6 - Foto esquerda: Estado das calçadas na rua João Rodrigues Filho. Foto direita: Estado da calçada na rua SP-132 -

Fonte: Autoras (2019)

Falta de qualidade nas áreas públicas (ruas)

Falta de arborização - sombreamento

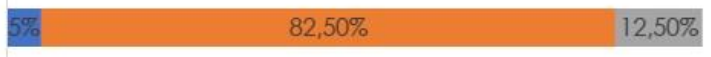

Não apropriação da calçada e rua (permanecer, conversar com o vizinho, etc)

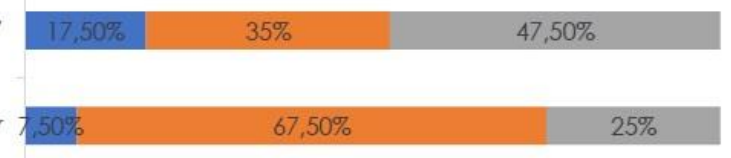

Ruas e calçadas desconfortáveis para caminhar

Ciclovias descontinuas

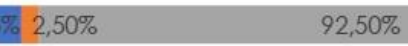

-Pouco = Muito =Não se aplica

Figura 7 - Gráfico do grau de incômodo em relação à falta de qualidade das áreas públicas (ruas e calçadas) -

Fonte: Autoras (2019) 


\section{Áreas de Lazer Desqualificada}

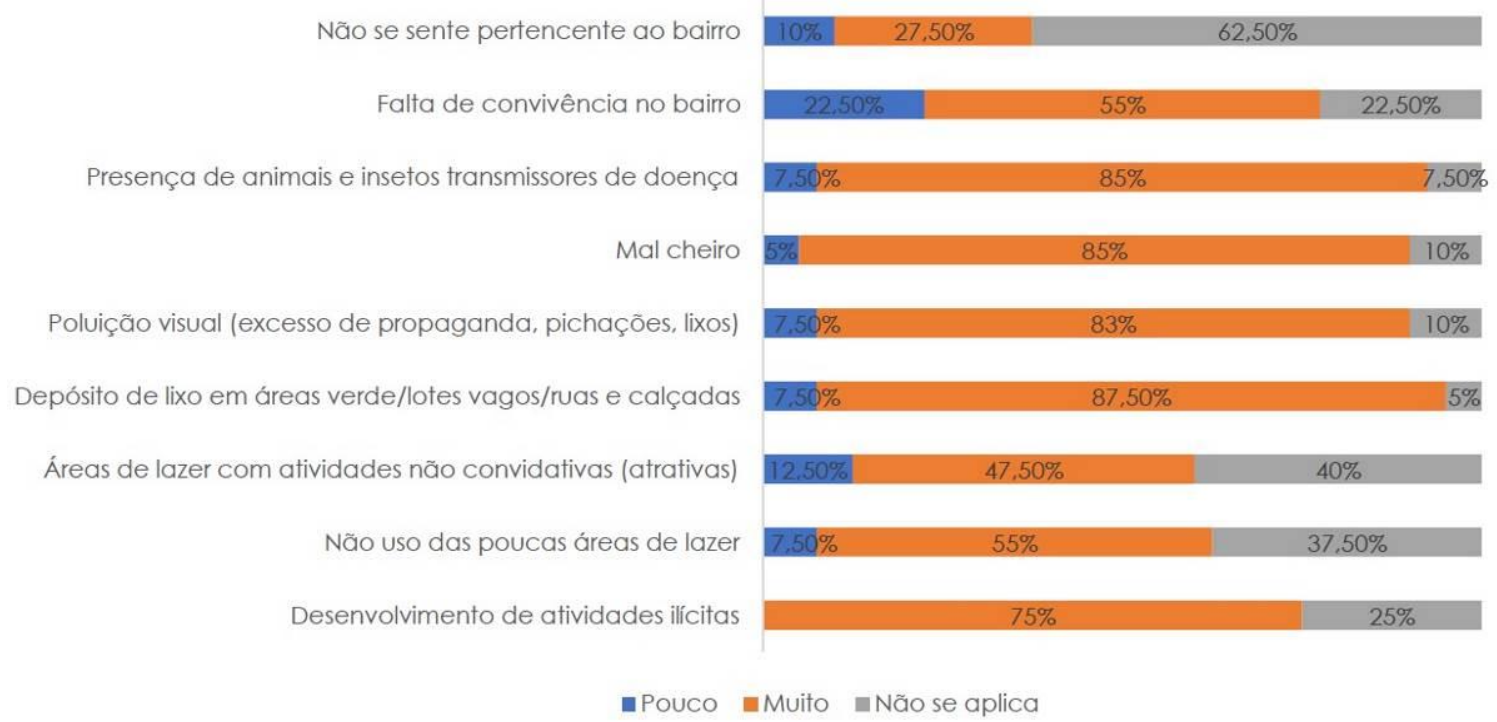

Figura 8 - Gráfico do grau de incômodo em relação à desqualificação das áreas de lazer -

Fonte: Autoras (2019)

Todos esses impactos relacionados a falta de qualidade urbanística das áreas públicas e até mesmo a própria falta de espaços públicas de lazer se relacionam diretamente com todos os indicadores do $5 \mathrm{~W}$, uma vez que os moradores acabam por se isolarem em suas casas e se sentem pouco a vontades a terem relações sociais com os vizinhos (conectar e doar), prejudicando o sentimento de identidade, sensação de pertencimento, com o bairro (tomar conhecimento). Não se sentem à vontade e seguros para usarem os equipamentos de lazer, desenvolver algumas das atividades, como praticar um esporte, ou somente caminhar nas ruas e calçadas (ser ativo, continuar aprendendo).

Também se observa que, objetivando o atendimento às suas necessidades, os moradores realizam algum tipo de modificação e/ou melhorias utilizando recursos próprios, essas reformas são feitas sem a assistência técnica especializadas. Essa autoconstrução e a ausência de planejamento interfere no conforto e salubridade, tendo em vista que o desperdício de material e geração de rejeitos que acabam sendo despejados nas calçadas, ruas, lotes vagos, entre outros (Figura 7).

O MCMV apresenta como parâmetro de família a nuclear tradicional (pai, mãe e dois filhos), limitando assim as dimensões e compartimentação da casa. Esse fato gera insatisfação por parte dos moradores $175,5 \%$ em relação ao tamanho dos cômodos e $72,5 \%$ consideram a quantidade de quartos insuficiente para o perfil familiar), o que pode prejudicar diretamente o bemestar dos usuários, já que os ambientes não atendem as suas reais necessidades, uma vez que existem variados perfis de famílias (Figura 8).

O tamanho reduzido dos cômodos limita a convivência e bom desempenho das atividades, uma vez que não há espaço suficiente para todos (VILLA, S. B.; et al.,2017). O que acaba prejudicando as relações familiares, que está ligada ao conectar, continuar aprendendo, tomar conhecimento indicadores do bem-estar, à medida em que começa apresentar sobreposição de atividades 
nos ambientes, ou seja, desenvolvimento de atividades diferentes em um mesmo ambiente e períodos iguais.

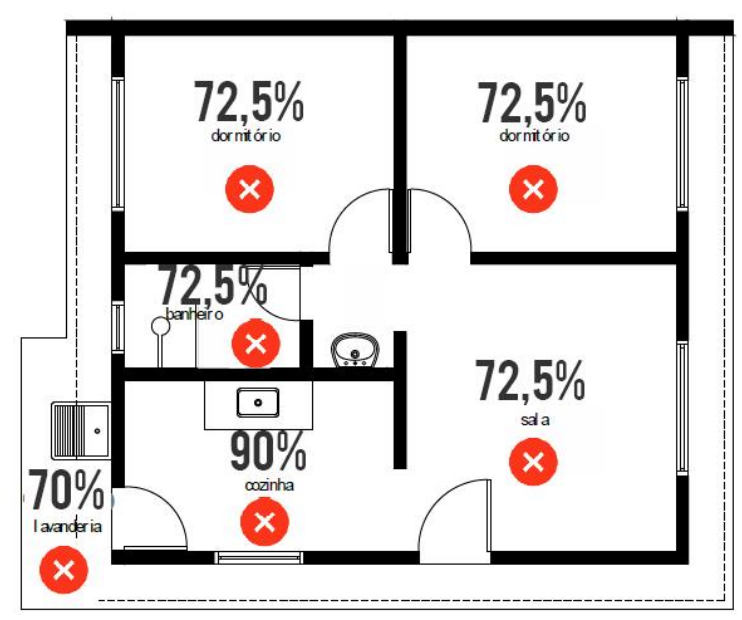

Figura 9 - Insatisfação dos moradores em relação ao tamanho de cada ambiente Fonte: Autoras (2019)

A partir desta análise alguns tipos de sobreposição de atividades interfere diretamente no indicador conectar, desenvolvendo um ambiente estressante e com pouca conexão entre os moradores (família) e pouca privacidade o que está ligado ao indicador tomar conhecimento, visto que pela falta de espaço pode interferir no seu desenvolvimento pessoa de forma negativa.

A pesquisa pretende avançar na área em três medidas principais: (i) analisar o bem-estar como um atributo da resiliência no ambiente construído focado no ponto de vista do usuário-morador e sua capacidade adaptativa; (ii) desenvolver instrumentos computacionais tecnológicos e aplicativos de APO para sua análise e disponibilização dos resultados; (iii) contribuir de forma prática e direta ao usuário e sua assistência técnica para melhoria do bemestar (5W) ampliando sua resiliência.

\section{CONSIDERAÇÕES FINAIS}

É possível notar a partir de alguns dos resultados até o presente momento da pesquisa, sob a ótica dos $5 \mathrm{~W}$, a existência de princípios de resiliência, por parte dos moradores nas habitações no Shopping Park, uma vez que mesmo frente as suas limitações acabam adaptando-se nos ambientes em busca de melhorar o seu bem-estar. Porém, nem sempre suas necessidades são satisfeitas após tais modificações, pois, surge novos problemas devido à realização de intervenções sem assistência técnica qualificada. Podendo perceber que o ambiente construído das unidades habitacionais não permite de forma satisfatória o desenvolvimento dos $5 \mathrm{~W}$ geradores de bem-estar.

Nota-se aqui a importância de um ambiente resiliente que permita diferentes configurações, visto que existe diferentes perfis de usuários e diversas realidades. Este falo torna-se altamente importante em um contexto de mudanças, sejam elas climáticas, demográficas, ou de modo de vida. $O$ ambiente construído pode e deve responder de forma positiva as necessidade e desejos dos usuários. 
Entendendo assim, que o ambiente construído interfere diretamente no bemestar dos moradores, a pesquisa de mestrado vê a necessidade de investigar sobre o bem-estar dos moradores por meio dos indicadores dos $5 \mathrm{~W}$. Afim de entender como o ambiente construído pode proporcionar bem-estar, de modo que possa desenvolver soluções e estratégias direcionadas aos moradores que contemplem $5 \mathrm{~W}$ gerando bem-estar e espaços mais resilientes.

\section{REFERÊNCIAS}

AKED, J. et al. Five ways to wellbeing: The evidence. October, 2008. Disponível em: <https://neweconomics.org/2008/10/five-ways-to-wellbeing-theevidence>. Acesso em: 05 nov. 2018.

AKED, J.; THOMPSON, S. 'Five ways to wellbeing: New applications, new ways of thinking', in which this project features as a 'case study'. Due July 2011. Disponível em: <https://neweconomics.org/201 1/07/five-ways-well-newapplications-new-ways-thinking>. Acesso em: 05 nov. 2018.

AMORE, C. S.; SHIMBO, L. Z.; RUFINO, M. B. (Org) Avaliação do Programa Minha Casa Minha Vida em seis estados brasileiros. Rio de Janeiro: Letra Capital, 2015.

ARUP; THE ROCKEFELLER FOUNDATION. City Resilience Index, 2015, 16 p. Disponível em:

<https://www.arup.com/perspectives/publications/research/section/cityresilience-index>. Acesso em: 27 set. 2019.

COLE, R. J. Building environmental assessment methods: redefining intentions and roles. Building Research \& Information, v.33, n. 5, p. 455-467, 2005.

DRESCH, A.; LACERDA, D. P.; JUNIOR, J. A. Design Science Research: método de pesquisa para avança da ciência e tecnologia. Porto Alegre: Bookman, 2015.

ELIAS-TROSTMANN, K. et al. Mais Fortes que a Tempestade: Aplicando a Avaliação de Resiliência Comunitária Urbana aos eventos Climáticos Extremos. World Resources Institute, 2018.

FGV; INSTITUTO ESCOLHAS. MORAR LONGE: o Programa Minha Casa Minha Vida e a expansão das Regiões Metropolitanas. Janeiro, 2019.

GARCIA, E.; VALE, B. Unravelling sustainability and Resilience in the environment. New York: Routledge, 2017.

LEAMAN, A.; BORDASS, W.; ELEY, J. A guide to feedback and post-occupancy evaluation. Usable Buildings Trust, 2006. Disponível em: <http://goodhomes.org.uk/downloads/members/AGuideToFeedbackAndPost OccupancyEvaluation.pdf>. Acesso em: 27 set. 2019.

LEMOS, M. F. Sustentabilidade e Resiliência. In: III ENANPARQ. Arquitetura, Cidade e Projeto: uma construção coletiva, 2014, São Paulo. Anais do III ENANPARQ. Arquitetura, Cidade e Projeto: uma construção coletiva. São Paulo: ANPARQ, 2014. p. 1-14.

MAGUIRE, B.; CARTWRIGHT, S. Assessing a community's capacity to manage change: A resilience approach to social assessment. Canberra: Australian Government Bureau of Rural Sciences. 2008. 
MALLORY-HILL, S.; PREISER, W. F.E.; WATSON, C. (edits). Enhancing Building Performance. Oxford, UK: Wiley-Blackwell, 330p, 2012.

ONO, R.; ORNSTEIN, S. W.; VILLA, S. B.; FRANÇA, A. J. G. L. (Org.) Avaliação PósOcupação (APO) na Arquitetura, no Urbanismo e no Design: da Teoria à Prática. São Paulo: Oficina de Textos, 2018.

ORNSTEIN, S. W. Arquitetura, Urbanismo e Psicologia Ambiental: uma reflexão sobre dilemas e possibilidades da atuação integrada. São Paulo: Revista Psicologia USP: Editora da Universidade de São Paulo, v. 16 (1/2), 2005, p. 155165.

PICKETT, S. T. A. et al. Ecological resilience and resilient cities. Building Research \& Information, 42:2, 143-157, 2014. DOI: 10.1080/09613218.2014.850600. Disponível em: <http://dx.doi.org/10.1080/09613218.2014.850600.>

STEEMERS, K. Architecture for Well-being and Health. Daylight \& Architecture, July 2015. Disponível em: <http://thedaylightsite.com/architecture-for-wellbeing-and-health/>.

STEVENSON, F.; BARBORKSA-NAROZNY, M. Technical and Social Redundancy for Low Carbon Living. In: Architecture and Resilience on a Human Scale Conference 2015, 2015, Sheffield - Reino Unido. Architecture and Resilience on a Human Scale Conference 2015. Sheffield, Reino Unido: Sheffield School of Architecture (September 10, 2015), 2015. v. 1. p. 13-23.

VILLA, S. B. et al. Método de análise da resiliência e adaptabilidade em conjuntos habitacionais sociais através da avaliação pós-ocupação e coprodução. Relatório Final De Pesquisa: Uberlândia: Universidade Federal de Uberlândia; Universidade de Sheffield, 2017.

VILLA, S. B.; ORNSTEIN, S. W. (Org.) Qualidade ambiental na habitação: avaliação pós-ocupação. São Paulo: Oficina de Textos, 2013. p.359-378.

VILLA, S. B.; SARAMAGO, R. C. P.; GARCIA, L. C. Avaliação Pós-Ocupação no Programa Minha Casa Minha Vida: uma experiência metodológica. 1. ed. Uberlândia: Universidade Federal de Uberlândia, 2015. v. 1. 152p. 